\title{
Study on the Economic Effects of China-SAARC FTA: Based on GTAP Model
}

\author{
Wang Rong-bo ${ }^{1, a,{ }^{*}}$ Zhang Jun 2, b \\ ${ }^{1}$ School of Economics, Guizhou University of Finance and Economics, Guiyang, Guizhou, China \\ ${ }^{2}$ Graduate School, Guizhou University of Finance and Economics, Guiyang, Guizhou, China \\ Email: awangrongbo1234@126.com, b1173065850@qq.com \\ *Wang Rong-bo
}

Keywords: The belt and road initiative; SAARC; Trade liberalization; Economic effects; GTAP model

\begin{abstract}
SAARC countries are the important areas in the construction of " the Belt and Road Initiative ". Promoting trade liberalization between China and SAARC will inject new vigor into the economic and trade development of both sides. GTAP model was used to evaluate the prospects of trade liberalization between China and SAARC. The study found that: On the whole, trade liberalization between China and SAARC promotes the economic growth and welfare level as well as import and export trade on both sides. As for industry influence, the textile industry among China, Bangladesh and Pakistan, planting industry in India, light industry in Sri Lanka, and the rest of the SAARC food processing industry are increased the most obviously in the domestic output level and export growth level. However, China's planting, resource and light industries will be adversely affected. Based on the above information, this paper puts forward the policy proposal of promoting trade liberalization of both sides under the background of "B\&R".
\end{abstract}

\section{基于 GTAP 模型的中国-南盟自贸区经济效应研究}

\author{
王容博 ${ }^{1, a, *}$, 张军 ${ }^{2, b}$ \\ 1 贵州财经大学经济学院, 贵阳, 贵州, 中国 \\ 2 贵州财经大学研究生院, 贵阳, 贵州, 中国 \\ Email: awangrongbo1234@126.com, b1173065850@qq.com \\ *王容博
}

关键词: 一带一路; 南盟; 贸易自由化; 经济效应; GTAP 模型

中文摘要：南盟国家是 “一带一路” 建设的重要区域, 推进中国与南盟贸易自由化将为双方 的经贸发展注入新的活力。本文运用 GTAP 模型, 对中国与南盟贸易自由化经济前景进行预 测评估, 研究结果显示, 从整体上看, 中国与南盟贸易自由化对双方的经济增长、福利水平 以及进出口贸易将产生明显的促进作用。从产业上看, 中国、孟加拉以及巴基斯坦的纺织 业、印度的种植业、斯里兰卡的轻工业以及南盟其他国家的食品加工业, 其国内产出水平以 及出口贸易水平增长最为显著。但中国的种植业、资源类产业以及轻工业将会受到明显冲 击。据此, 在 “一带一路” 建设背景下, 提出推进双方贸易自由化的政策建议。 
1. 引言

南盟是南亚区域合作联盟（South Asian Association for Regional Cooperation）的简称， 于 1985 年 12 月在孟加拉首都达卡成立。目前, 南盟有印度、巴基斯坦、孟加拉、斯里兰 卡、尼泊尔、阿富汗、马尔代夫、不丹八个成员国。其中，印度、巴基斯坦、尼泊尔、不 丹、阿富汗等五个国家与中国在陆上接壤。古代的“南方丝绸之路”、“茶马古道”等通道将中 国与南亚国家紧密联系在一起, 双方商贸往来频繁。如今中巴、孟中印缅两条经济走廊与推 进“一带一路”建设关联紧密。其中，中巴经济走廊北接“丝路经济带”，南连“21 世纪海上丝 绸之路”，是贯穿南北丝路的关键枢纽，成为中巴深层经贸合作的新平台。在全球经济增长 长期放缓的背景下, 南亚地区经济增长仍然活力高涨, 市场前景广阔, 中国与南盟加强区域 经济合作，实现贸易自由化，将为双方的经贸发展注入新的活力。

\section{2. 文献综述}

从古至今，中国与南亚国家经贸往来和文化交流不断。国内外学者对于双方经贸关系的 研究取得了大量的成果。从研究内容上看, 现有文献大多从以下几个方面进行研究: 双方的 贸易现状、贸易关系的影响因素以及合作前景的理论分析。滕纳康和图斯塔(Tennakoon \& Thusita,2012）认为中国与南亚经贸取得了快速发展，同时贸易不平衡越来越严重，中国应 该对南亚的出口实行优惠性市场准入, 以平衡双方之间的贸易差额。 ${ }^{[1]}$ 杨立强和高巍 （2010）在分析中国与巴基斯坦经贸合作的基础之上，探讨中国在南亚的战略利益与经济合 作目标, 认为中国应继续推进中巴自贸区建设, 加强与印度的经贸合作, 以此推进中国与南 亚的区域经济合作。[2]李迎旭（2016）就中国与南亚贸易合作的竞争性和互补性进行分析, 认为中国对南亚的经贸关系密切, 但是南亚对中国的贸易有待进一步加强, 与此同时, 中国 与南亚商品贸易的互补性不断增大，合作潜力广泛，双方应该积极借助“一带一路”倡议的东 风，通过基础设施建设，扩大投资，加强贸易制度安排，进一步推进双方的经贸发展。 ${ }^{[3]}$ 还 有众多学者以南亚具体国家为研究对象, 研究中国与其经贸关系的影响因素。如李慧玲等

（2016）运用 CMS 模型研究中印、中巴双边的贸易增长因素，研究认为印度和巴基斯坦的 市场需求引致效应是中国对这两国出口增长的主要影响因素, 但是就总的增长效应来看, 中 国对巴基斯坦出口增长的总效应低于印度。 ${ }^{[4]}$ 此外，对于中国和南亚单一国家构建自贸区的 设想也有学者做过具体研究, 如李丽, 陈迅 (2008) 运用 GTAP 模型模拟预测中国与印度自 由贸易区建立的经济影响, 研究结果认为, 中印自贸区的建立将促进双方的产业间与产业内 贸易的发展, 中国的居民福利水平与 GDP 都有所提高, 但中国的服务贸易将受到较大冲 击。[5]

以往学者对于中国与南盟的经贸合作更多的是偏重于定性分析, 在新的历史时期下, 中 国与南盟通过消减关税加强区域经贸合作的实证研究鲜有涉猎。区域经济合作是目前国际经 济一体化发展的主流趋势, 各国都在积极构建自己的区域合作蓝图（张涁等，2009）。[6]中 国与南盟合作基础稳定，合作前景广阔（何智娟，2012）。[7]因此，笔者运用 GTAP 模型， 通过模拟冲击关税政策, 分析中国与南盟实现贸易自由化将产生的经济效应、福利效应以及 微观产业效应, 以此分析中国与南盟自由贸易区建设的可行性, 以期为中国南盟进一步加强 区域合作建言献策。

\section{GTAP模拟方案设计}

\section{1 数据说明}

GTAP（Global Trade Analysis Project）模型是由美国普渡大学 Thomas W. Hertel 教授根 据新古典经济理论主持设计的多国多部门一般均衡模型, 该模型已被广泛用于分析国际贸易 政策。笔者将运用 GTAP8.02 数据库以及 RunGTAP3.69 软件，模拟分析中国与南盟实现贸 
易自由化对双方产生的经济效应。GTAP8.02 数据库以 2007 年作为基期, 包含 127 个国家和 地区，5 个基本要素以及 57 个产业部门。

\section{2 模拟方案设定}

根据中国与南盟贸易市场的集中度, 将 GTAP 数据库中的国家和地区重新划分为 8 个地 区：中国、印度、巴基斯坦、孟加拉、斯里兰卡、尼泊尔、南盟其他国家以及世界其他国 家。同时借鉴刘文革, 王文晓（2014）的分类方法, 将 57 个行业分为十大部门, 具体如表 1 所示。[8]基于上述的地区与部门分类, 基准方案的关税维持在 2007 年基期的水平, 模拟方 案为中国与南盟建立自由贸易区，取消各国之间的进出口关税，实现贸易自由化。

表 1 GTAP 部门分类

\begin{tabular}{|c|c|}
\hline 部门 & 包含的产品 \\
\hline 种植业 & $\begin{array}{l}\text { 稻谷、小麦、其他谷物、蔬菜水果、油脂作物、甘蔗甜菜、植物性纤维、其他农作物、稻 } \\
\text { 米加工制品 }\end{array}$ \\
\hline 畜牧业 & 牛羊马等畜产及其肉制品、其他动物制品、生乳、羊毛䖯茧等、其他肉及其制品 \\
\hline 资源产业 & 林业、渔业、煤炭、石油、天然气、其他矿产品 \\
\hline 食品加工业 & 植物油脂、乳制品、糖制品、其他食品、饮料、酒水及烟草 \\
\hline 纺织服装业 & 纺织品、服装 \\
\hline 轻工制造业 & $\begin{array}{l}\text { 皮革制品、木制品、纸制品及印刷品、金属制品、机动车及其零部件、其他运输设备、其 } \\
\text { 他制成品 }\end{array}$ \\
\hline 重工制造业 & $\begin{array}{l}\text { 石油及煤炭产品、化工产品、橡胶及塑料制品、其他矿产品、铁类金属、其他金属、电气 } \\
\text { 设备、其他机械设备 }\end{array}$ \\
\hline 基础服务业 & 电力、燃气、供水、建筑 \\
\hline $\begin{array}{l}\text { 运输通讯服务 } \\
\text { 业 }\end{array}$ & 贸易服务、陆运、海运、空运、其他运输、通讯 \\
\hline 其他服务业 & $\begin{array}{l}\text { 金融服务业、保险业、其他商业服务、娱乐及其他服务、公共管理和社会保障、文化教育 } \\
\text { 及医疗卫生 }\end{array}$ \\
\hline
\end{tabular}

资料来源: 根据 GTAP8.02 数据库整理得出。

\section{4. 实证结果分析}

\section{1 宏观层面分析}

\subsection{1 对各国的总体影响}

贸易自由化对各国的总体影响主要从 GDP 变化率，进出口变化率，贸易条件，贸易平 衡, 社会福利水平这几个方面来分析（张静中，王文君，2016）。[9]具体的模拟结果如表 2 所示。从 GDP 的变化率来看, 双方实现贸易自由化之后, 中国的 GDP 将会增长 $0.3084 \%$ 。 而南盟除了巴基斯坦与斯里兰卡两个国家的 GDP 会受到一定冲击之外, 其他成员国的 GDP 都将有不同程度的增长, 其中增长幅度最为显著的是尼泊尔, 贸易自由化使其 GDP 增加 4.1444 个百分点。世界其他国家或地区的 GDP 受到的影响相对较小。整体上看, 贸易自由 化有利于双方总体经济水平的提升。

中国与南盟实现贸易自由化对双方的进出口将产生显著的促进作用。贸易自由化使得中 国进口额与出口额分别增长 $0.7065 \%, 0.5909 \%$ 。就南盟而言, 各成员国进出口额增加幅度 远大于中国, 这主要是因为南盟国家同中国贸易依赖性较强。总的来说, 贸易自由化使得中 国与南盟产生了 “贸易创造” 效应。由于中国出口增加额大于进口增加额, 贸易平衡将增加 4.52 亿美元。而南盟国家却相反, 进口增加额超过了出口增加额, 使得贸易平衡变化额为 负。从贸易条件变化情况来看, 孟加拉、斯里兰卡、巴基斯坦的贸易条件有不同程度的恶 化, 中国与南盟其他国家的贸易条件都将得到改善。 
在 GTAP 模型中，用收入等值（Equivalent Variation, EV）来表示社会总体福利(孙人 极, 顾研, 2017)。[10]从福利水平变动情况来看, 中国与南盟各国的福利水平都将有所提 升, 其中中国与印度上升的最多, 分别为 37.67 亿美元与 14.82 亿美元, 南盟其他各成员国 的福利水平也都有不同程度的增加, 但世界其他国家的福利水平将有所下降。由此可以看 出, 中国与南盟贸易自由化符合双方社会发展的根本利益, 但是对世界其他国家将产生一定 的负面影响。

表 2 中国南盟贸易自由化对各国家和地区的总体影响（单位：\%）

\begin{tabular}{|c|c|c|c|c|c|c|}
\hline 国家 & GDP (\%) & 进口（\%) & 出口（\%) & 贸易条件 (\%) & $\begin{array}{c}\text { 贸易平衡 } \\
\text { (百万美元) }\end{array}$ & $\begin{array}{c}\text { 福利水平 } \\
\text { (百万美元) }\end{array}$ \\
\hline 中国 & 0.3084 & 0.7065 & 0.5909 & 0.2186 & 452.0149 & 3767.3208 \\
\hline 印度 & 0.1368 & 2.4329 & 2.8169 & 0.0118 & -525.9755 & 1482.0864 \\
\hline 孟加拉 & 0.0246 & 8.0750 & 9.0647 & -1.3186 & -252.6238 & 70.8615 \\
\hline 巴基斯坦 & -0.0414 & 3.5166 & 5.4068 & -0.2062 & -315.8192 & 5.3712 \\
\hline 尼泊尔 & 4.1444 & 15.3386 & 23.0456 & 1.9045 & -153.2602 & 180.7084 \\
\hline 斯里兰卡 & -0.3886 & 3.7163 & 2.6957 & -0.2447 & -243.3272 & 58.9899 \\
\hline 南盟其他国家 & 2.1758 & 4.4742 & 5.8698 & 1.7905 & -97.3160 & 92.9075 \\
\hline 世界其他国家 & -0.0386 & -0.0559 & -0.0483 & -0.0185 & 1136.2557 & -2558.9421 \\
\hline
\end{tabular}

数据来源: GTAP 模拟结果整理得出。

\subsection{2 对双边贸易的影响}

表 3 显示了中国与南盟贸易自由化对双方各国以及其他地区双边贸易产生的总体影响。 从表中可以看出, 中国对印度、巴基斯坦、孟加拉三个国家的出口增加最为明显, 分别增加 148.37 亿美元，29.9 亿美元，17.58 亿美元。与此同时, 中国对世界其他国家的出口将有所 下降。但是将中国的所有出口进行加总, 可以看出中国的总出口额将增加 50.81 亿美元。从 中国进口来看, 中国除了对尼泊尔的进口有轻微下降之外, 对于其他南盟国家的进口都将上 升, 中国进口增加总额为 68.55 亿美元。从总体上看, 贸易自由化对南盟各国之间的进出口 贸易将起到不同程度的促进作用。其中印度、孟加拉、斯里兰卡三个国家对南盟各成员国的 出口额都将增加, 巴基斯坦除了对尼泊尔的出口有轻微下降之外，对其他成员国的出口也都 有不同程度的增加。由于尼泊尔与印度三面接壤, 实现贸易自由化, 尼泊尔与印度之间的贸 易将会明显增加, 进口与出口分别增加 4.39 亿美元与 3.45 亿美元, 而尼泊尔与其他国家之 间的贸易受到影响相对较小。

表 3 中国南盟贸易自由化对各国家和地区双边贸易的总体影响（单位：百万美元）

\begin{tabular}{|c|c|c|c|c|c|c|c|c|}
\hline 出口/进口 & 中国 & 印度 & 孟加拉 & 巴基斯坦 & 尼泊尔 & 斯里兰卡 & 南盟其他国家 & 世界其他国家 \\
\hline 中国 & 0 & 14837.4293 & 1758.2414 & 2989.8148 & 95.4764 & 296.5771 & 67.2622 & -14963.3876 \\
\hline 印度 & 2480.2251 & 0 & 977.2156 & 708.0082 & 438.9337 & 1048.8846 & 118.8002 & 229.5617 \\
\hline 孟加拉 & 33.5075 & 88.8014 & 0 & 28.5004 & 0.4203 & 3.1351 & 1.6331 & 1317.1788 \\
\hline 巴基斯坦 & 265.7733 & 265.0154 & 145.6773 & 0 & -0.0333 & 69.4379 & 138.4746 & 271.039 \\
\hline 尼泊尔 & -2.1624 & 345.2447 & -0.0064 & 0.099 & 0 & 0.0059 & -0.0199 & -91.1241 \\
\hline 斯里兰卡 & 22.3021 & 20.3619 & 15.8163 & 19.0992 & 0.1412 & 0 & 99.32 & 99.3651 \\
\hline 南盟其他国家 & 1.0281 & 215.6566 & 10.5147 & 36.4625 & -0.0549 & 8.9599 & 0 & -164.7073 \\
\hline 世界其他国家 & 4053.9279 & -9714.4279 & -1655.2462 & -2635.3985 & -194.7296 & -1109.6437 & -222.0712 & 0 \\
\hline
\end{tabular}

数据来源: GTAP 模拟结果整理得出。 


\section{2 微观层面分析}

\subsection{1 对各国不同产业产出的影响}

表 4 给出了中国与南盟贸易自由化对各国家不同产业产出的影响。由于各国产业结构与 要素禀赋的差异, 贸易自由化对其国内产出的影响也各异。整体上看, 南盟各国劳动力资源 充裕, 经济大多以农业为主, 工业基础薄弱。因此中国与南盟贸易自由化将对中国的种植 业、资源产业、食品加工业以及轻工制造业产生一定的冲击, 而对我国的纺织服装业、基础 服务业、重工制造业等产生一定的正面影响。具体而言, 贸易自由化之后, 我国的种植业产 出减少 $0.2191 \%$, 资源产业减少 $0.1129 \%$, 食品加工业、轻工制造业、交通通讯服务业也将 受到小幅度冲击。而纺织服装业产出增加 $0.2344 \%$, 基础服务业增加 $0.1037 \%$, 其他行业的 产出也都有不同程度的增长。

贸易自由化对南盟国家各部门的产出影响各不相同。印度、巴基斯坦、尼泊尔的种植业 产出将分别增长 $0.497 \% 、 0.2887 \% 、 0.1221 \%$, 而孟加拉与斯里兰卡的种植业产出将会受到 较明显的冲击。这主要是因为贸易自由化使得有限的国内资源将更多地分配到自己的优势产 业中去, 实现资源最优配置。对于劳动力充裕的南盟, 贸易自由化使得孟加拉、巴基斯坦的 纺织服装业产出分别增加 3.0692 与 1.0706 个百分点。

表 4 中国南盟贸易自由化对各国家和地区国内产出的影响（单位：\%）

\begin{tabular}{|c|c|c|c|c|c|c|c|c|}
\hline 产业 & 中国 & 印度 & 孟加拉 & 巴基斯坦 & 尼泊尔 & 斯里兰卡 & 南盟其他国家 & 世界其他国家 \\
\hline 种植业 & -0.2191 & 0.4970 & -0.3103 & 0.2887 & 0.1221 & -1.0727 & 0.9830 & -0.0502 \\
\hline 畜牧业 & 0.0066 & -0.0697 & -0.2914 & -0.0935 & 0.9344 & 0.4589 & -0.2250 & 0.0134 \\
\hline 资源产业 & -0.1129 & -0.0450 & -0.3668 & -0.3697 & -1.9567 & 0.0133 & -0.0399 & 0.0036 \\
\hline 食品加工业 & -0.0094 & 0.1338 & -0.4885 & 0.1384 & 8.4157 & -0.3703 & 3.9315 & -0.0037 \\
\hline 纺织服装业 & 0.2344 & -1.2397 & 3.0692 & 1.0706 & -6.6641 & -0.8586 & -1.0402 & -0.0660 \\
\hline 轻工制造业 & -0.0907 & -0.0504 & -3.3170 & -2.0028 & -13.5987 & 3.9073 & -2.3956 & 0.0166 \\
\hline 重工制造业 & 0.0910 & -0.3111 & -4.3339 & -1.7607 & 15.3183 & -1.5180 & 3.1853 & -0.0076 \\
\hline 基础服务业 & 0.1037 & 0.2533 & 0.6257 & 0.3369 & 3.5501 & 1.7521 & 1.1370 & -0.0086 \\
\hline 交通与通讯服务业 & -0.0405 & -0.0196 & -0.2894 & -0.0426 & -0.9795 & 0.3618 & -0.9148 & 0.0082 \\
\hline 其他服务业 & 0.0114 & -0.1222 & -0.4129 & -0.0782 & -0.4533 & -0.2504 & -0.5064 & 0.0009 \\
\hline
\end{tabular}

数据来源: GTAP 模拟结果整理得出。

4.2.2 对各国不同产业进出口贸易的影响

表 5 与表 6 分别给出了中国南盟贸易自由化对双方各产业进出口贸易的影响。从进口来 看, 中国对各行业的进口额都有所增加。其中对农产品的进口增长幅度最大, 达到 $3.1937 \%$; 其次是纺织服装业, 达到 $1.516 \%$; 其他行业也有不同程度的增长。就南盟国家而 言, 印度、孟加拉、巴基斯坦与尼泊尔这四个国家在纺织服装业的进口增长幅度最为明显, 分别达到 $26.5864 \% 、 30.3698 \% 、 26.4289 \% 、 17.0451 \%$ 。除此之外, 尼泊尔的种植业、畜牧 业、资源产业、食品加工业等增加幅度也相对较大, 均超过了 $20 \%$ 。总的来说, 贸易自由化 对中国以及南盟各国的不同产业进口产生了促进作用。

从出口方面来看, 贸易自由化使得中国在不同行业上的出口受到的影响各异。种植业、 资源产业、纺织服装业与重工制造业的出口将有一定程度的增加, 而其他行业则受到负面冲 击。受到冲击最明显的是服务业, 降低幅度超过了 $1 \%$ 。南盟国家劳动力与自然资源相对丰 富, 贸易自由化有利于劳动密集型产业的出口, 例如印度、孟加拉和尼泊尔的种植业出口将 分别增加 $16.8406 \%$ 、13.8691\%和 $118.1172 \%$ 。但是南盟各国的服务业出口将有所下降。从 整体上看，贸易自由化对南盟国家各产业出口的正面影响超过负面影响。 
表 5 中国南盟贸易自由化对各国家和地区进口贸易的影响（单位：\%）

\begin{tabular}{|c|c|c|c|c|c|c|c|}
\hline 产业 & 中国 & 印度 & 孟加拉 & 巴基斯坦 & 尼泊尔 & 斯里兰卡 & 南盟其他国家 \\
\hline 种植业 & 3.1937 & 6.4086 & 4.6131 & 4.2754 & 31.4388 & 11.2066 & 14.5623 \\
\hline 畜牧业 & 0.7383 & 4.0505 & 4.5239 & 3.8289 & 34.4908 & 1.8848 & 9.9586 \\
\hline 资源产业 & 0.5535 & -0.0876 & -2.1234 & -2.2219 & 29.3351 & -1.6409 & 30.6960 \\
\hline 食品加工业 & 0.7674 & 3.6868 & 2.2378 & 2.5559 & 28.1906 & 5.2750 & 4.5007 \\
\hline 纺织服装业 & 1.5160 & 26.5864 & 30.3698 & 26.4289 & 17.0451 & -0.3201 & 3.0759 \\
\hline 轻工制造业 & 0.8920 & 2.5786 & 8.4387 & 4.3201 & 31.2867 & 4.6030 & 3.3821 \\
\hline 重工制造业 & 0.6769 & 3.8873 & 2.6929 & 2.9490 & 6.0592 & 3.0437 & 2.3945 \\
\hline 基础服务业 & 0.6584 & -0.1471 & 2.5362 & 0.8796 & 17.8039 & 2.0272 & 5.6083 \\
\hline 交通与通讯服务业 & 0.5857 & 0.2506 & 1.1726 & 0.2264 & 8.2910 & 0.7807 & 4.3490 \\
\hline 其他服务业 & 0.6000 & 0.2648 & 1.1072 & 0.4509 & 8.2999 & 1.4599 & 3.2301 \\
\hline
\end{tabular}

数据来源: GTAP 模拟结果整理得出。

表 6 中国南盟贸易自由化对各国家和地区出口贸易的影响（单位：\%）

\begin{tabular}{|c|c|c|c|c|c|c|c|}
\hline 产业 & 中国 & 印度 & 孟加拉 & 巴基斯坦 & 尼泊尔 & 斯里兰卡 & 南盟其他国家 \\
\hline 种植业 & 1.2298 & 16.8406 & 13.8691 & 9.1146 & 118.1172 & 6.8647 & 22.3842 \\
\hline 畜牧业 & -0.9498 & -3.2424 & 9.3304 & -1.0020 & -26.8345 & 51.8479 & -7.5974 \\
\hline 资源产业 & 1.3382 & 1.5714 & 16.0797 & 12.8116 & 41.3835 & -0.3436 & 5.2951 \\
\hline 食品加工业 & -0.1866 & 5.0248 & 3.2749 & 9.7253 & 69.9758 & 3.3059 & 33.1914 \\
\hline 纺织服装业 & 0.6390 & 1.4939 & 13.3004 & 5.9184 & 6.4167 & -0.9844 & 15.9830 \\
\hline 轻工制造业 & -0.1995 & 2.8197 & 3.5840 & 8.3613 & 12.3963 & 13.0280 & 11.5454 \\
\hline 重工制造业 & 0.8426 & 5.2483 & 10.0585 & 10.6235 & 86.7798 & 10.1449 & 15.1295 \\
\hline 基础服务业 & -1.1610 & -0.2584 & -1.9348 & 0.3221 & -20.1464 & -0.9112 & -8.0572 \\
\hline 交通与通讯服务业 & -1.1060 & -0.4889 & -2.5902 & -0.4492 & -15.7737 & -1.3397 & -7.4904 \\
\hline 其他服务业 & -1.1591 & -0.7249 & -2.9975 & -1.1115 & -18.1419 & -3.5979 & -7.7831 \\
\hline
\end{tabular}

数据来源: GTAP 模拟结果整理得出。

\section{5. 结论与建议}

\section{1 结论}

运用 GTAP 模型模拟中国与南盟贸易自由化的经济效应、贸易效应以及产业效应，得出 以下结论: 从宏观经济上看, 中国与南盟贸易自由化将产生互利共赢的局面, 除了巴基斯坦 与斯里兰卡的 GDP 受到一定的冲击之外, 中国以及其他南盟国家的 GDP 都有不同程度的提 升, 与此同时, 各成员国的社会福利水平也将有较大提高。从进出口贸易上看, 贸易自由化 使得中国与南盟各国产生明显的 “贸易创造” 效应, 但由于进口额与出口额变动不一致, 使得 南盟各国贸易平衡额减少, 中国的贸易平衡额增加。除此之外, 贸易自由化对中国与南盟以 及南盟各成员国之间的双边贸易也将产生促进作用。就具体产业而言, 中国、孟加拉与巴基 斯坦的纺织业、印度的种植业、斯里兰卡的轻工业以及南盟其他国家的食品加工业, 其国内 产出水平以及出口贸易水平增长最为显著。不可否认, 贸易自由化也势必对各国的相关产业 造成不同程度的冲击, 但从整体效应上看, 中国与南盟贸易自由化利大于弊, 符合双方发展 的根本利益。

\section{2 建议}

目前, 任何一个国家都不能孤立地存在, 区域经济合作是经济全球化的主流趋势, 是各 国经济快速发展的必由之路。“一带一路”倡议给中国与南盟经贸合作提供了新的机遇, 结合 中国与南盟的贸易现状及模拟结果, 笔者尝试提出以下推进双方贸易自由化的政策建议:

第一, 加强互联互通, 挖掘经贸互补 
中国与南盟的产业结构存在较明显的差异。南盟市场广阔，其人口超过了全球总人口的 五分之一, 但是南盟整体上经济相对落后, 除印度外, 其他国家工业基体系尚不完善, 主要 出口初级产品与劳动密集型产品, 而中国对南亚国家主要出口资本及技术密集型的工业制成 品，双方的贸易结构具有较强的互补性（胡本海, 辛仁杰，2012）。[11]中国通过“一带一路” 加强对南盟基础设施建设、能源开发等重大项目合作, 不仅可以实现中国与南盟以及南盟成 员国之间的互联互通, 而且产生了良好的经济效应与社会效应, 为中国与南盟之间的贸易自 由化奠定基础。除此之外, 中国可向孟加拉、阿富汗、尼泊尔、不丹等欠发达国家转移低端 制造业，既可利用南盟充裕的劳动力资源，又可为中国发展高端制造业腾出空间。

第二，改善政治关系，增强政治互信

稳定的政治关系是区域经济一体化发展的重要保障, 中国与巴基斯坦经贸的快速发展, 就是得益于双方稳固的政治关系。中国与南盟国家政治关系整体良好, 这也是双方经贸稳步 发展与“一带一路”顺利推进的重要基础。但是由于领土, 文化, 历史等原因, 中国与印度的 政治关系仍有待进一步加强。因此, 中国与南盟国家应该通过多种渠道加强交流沟通, 巩固 政治关系。例如, 中国与南盟成员国政府可以通过“一带一路”倡议, 借助国际合作高峰论坛 等平台, 密切企业间合作和人文交流, 加强政治互信。除此之外, 各国企业与非政府组织的 合作交流，也将为改善政治关系起到重要的促进作用。

第三，借鉴现有的自贸区建设经验，加快正在谈判的自贸区进程

中国分别与巴基斯坦、马尔代夫先后签订了自由贸易协定，对中国与南盟自贸区的建设 产生了良好的示范效应。除此之外, 中国与南盟的合作可以借鉴中国与东盟的自贸区建设经 验, 从而可以降低风险。由于南盟国家内部政治利益的矛盾, 中国与南盟实现贸易自由化进 程势必不可一䟣而就（胡仕胜，2010）。[12]但自贸区建设产生的经济利益是各方合作的强大 动力, 中国可以加快与南盟正在谈判的自贸区进程, 如正在谈判的中国-斯里兰卡自贸区。 在此基础上逐步将中国南盟自贸区建设提上日程, 从而推动中国与南盟实现互利共赢、共同 发展。

第四，制定灵活的产业政策，逐步实现贸易自由化

中国与南盟贸易自由化促进双方经济增长，社会福利增加的同时，双方的相关产业难免 会受到冲击。因此贸易自由化的进程不可一步到位, 应分阶段实施。对于各国家的非敏感产 业, 如农业、矿物资源类产业、机械设备制造业等可先行通过降低关税等措施实行贸易自由 化。在初步合作的基础上分阶段对敏感类产业, 如纺织服装业、化工业等降低关税, 直到最 终实现贸易自由化。同时, 各方在自贸协定的谈判中, 应事先做好充分评估, 设定监督预警 机制，通过谈判争取到保护敏感产业的有利政策，达成互利共赢的合作方案。

\section{致谢}

本文为 2017 年度贵州省研究生科研基金立项课题《西南民族地区对外贸易与产业结构 升级的关系研究》（KYJJ2017026）阶段性研究成果之一。

\section{References}

[1] Tennakoon T. Addressing the Trade Imbalances[J]. Policy Perspectives, 2012, 9(1):129-133.

[2] Yang Liqiang, Gao Wei. China-Pakistan Free Trade Agreement and China's Strategy on Regional Economic Cooperation with South Asian Countries[J]. Asia-Pacific Economic Review, 2010, (01):16-20.

[3] Li Yingxu. The Base of Cooperation, Advancing Opportunities and Realizing Mechanisms for China-South Asia Trade under the Belt and Road Initiative [J]. Gan Su Social Sciences, 2016, (02):128-133. 
[4] Li Huiling, Ma Haixia, Chen Jun. Research on Growing Factors of Exports from China to India and Pakistan--Based on Revised CMS Model Under "the Belt and Road" Strategy[J]. Inquiry into Economic Issue, 2016, (03):127-135.

[5] Li Li, Chen Xun. Empirical Analysis of the Impact of China-India FTA's Construction China and the World Economy[J]. Finance and Trade Economics, 2008, (4):111-116.

[6] Zhang Bin, Wang Sheng, Yu Zhen. A Comparative Study on Welfare Effects of Participation of Developing Countries in International Economic Integration[M]. Beijing: Social Sciences Academic Press, 2009:71-88.

[7] He Zhijuan. Regional Cooperation between China and SAARC [J]. South Asian Studies Quarterly, 2011, (02):80-83.

[8] Liu Wenge, Wang Wenxiao. Analysis of the Feasibility and Economic Effect of Establishing FTA among the BRICS[J]. International Economics and Trade Research, 2014, (6):80-91.

[9] Zhang Jingzhong, Wang Wenjun. Impact of China-West Asia FTA: An Empirical Analysis Based on the Dynamic GTAP[J]. World Economy Studies, 2016, (8):70-78.

[10] Sun Renji, Gu Yan. The Influences on Economic, Trade and Industrial Aspects of China, Australia and New Zealand by the Sino-Aus FTA: Based on GTAP Simulation Analysis[J]. Asia-Pacific Economic Review, 2017, (01):77-84,165.

[11] Hu Benhai, Xin Renjie. South Asian Market Status and Features--the Potential of Commodity Trade in Yunnan and South Asian Countries[J]. Inquiry into Economic Issues, 2012, (06):73-80.

[12] Hu Shisheng. On the China SAARCR restraint Factors in Economic and Trade Cooperation and the Ways of Economic Integration[J]. Southeast Asian and South Asian Studies, 2010, (01):33-38. 